\title{
Rate of social anxiety disorder, its comorbidity with depression and paroxetine effects in outpatients in Japan*
}

\author{
Yukihiko Shirayama\#, Michio Takahashi, Masatoshi Suzuki, Atsushi Kimura, Koichi Sato
}

Department of Psychiatry, Teikyo University Chiba Medical Center, Ichihara, Japan

Email: " shirayama@rapid.ocn.ne.jp

Received 27 November 2012; revised 28 December 2012; accepted 7 January 2013

\begin{abstract}
The prevalence of persons with social anxiety disorder (SAD) in Japan remains unknown. This study examined 293 patients with age between 20 and 60 at first visit on the outpatient clinic of psychiatry by the section of social phobia of M.I.N.I. and DSM-IV. After that, 10 patients with both SAD out of 16 patients (trial recruited) completed 12 weeks of treatment with paroxetine. Among 63 patients with 4 points and 40 patients with 3 points on the M.I.N.I., 21 patients (33\%) and 16 patients $(\mathbf{4 0 \% )}$ ) were diagnosed as SAD on DSM-IV criteria, respectively. Together, 37 patients $(\mathbf{1 2 . 6 \% )}$ ) were diagnosed as SAD out of the 293 outpatients. Among 37 patients with SAD, 23 patients (62\%) had comorbid depression. As for 10 patients after treatment with paroxetine, 8 patients improved from the point of recovery of depression (HAM-D scores below 10), whereas only 4 patients improved from the point of recovery of social phobia (L-SAS scores below 30). Three points as well as 4 points on the M.I.N.I. is meaningful for the diagnosis of SAD. For a while, paroxetine exerted less beneficial effects on SAD rather than on depression.
\end{abstract}

Keywords: Social Anxiety Disorder; Depression; Paroxetine; Comorbidity

\section{INTRODUCTION}

Social Anxiety Disorder (SAD) is characterized by social phobia, the fear of being observed or evaluated by others [1]. The patients often avoid situations that cause intense stress, resulting in a reduced quality of life [2-4].

A previous study reported that the comorbidity of social phobia with major depression is $70 \%$ and that social phobia usually predates the mood disorder [5]. Another study reported that $35 \%$ of patients with social phobia had experienced at least one major depressive episode

\footnotetext{
${ }^{*}$ The authors declare no conflict of interest.

${ }^{\#}$ Corresponding author.
}

[6]. Recent studies reported that social phobia is one of the clinical factors in treatment-resistant depression [7] or subsequent onset of depression [8,9]. The existence of comorbid social phobia predicted the long-term bad outcome of major depressive disorder [10]. Furthermore, depression was found to be the robust predictor of treatmement-seeking SAD [11,12].

Pharmacotherapy is reported to be effective in the treatment of SAD, as reviewed by elsewhere $[5,13]$. Selective serotonin reuptake inhibitors (SSRI), including citalopram, sertraline, fluvoxamine and paroxetine, are known to be effective as well as benzodiazepines at the first-line pharmacologic treatment for SAD.

The purpose of this study was to examine the prevalence of SAD, its relationship with depression, and the clinical sensitivity of the Mini-International Neuropsychiatric Interview (M.I.N.I.) to SAD [14] at a first visit of patients to an outpatient clinic of psychiatry in Japan. Furthermore, we challenged the treatment with paroxetine to patients with both SAD and depression to examine pharmacological difference in response.

\section{METHODS}

\subsection{Subjects}

All patients were recruited from the outpatient psychiatry clinic of Teikyo University Chiba Medical Center from August 2010 to July $2011(\mathrm{~N}=293)$. The age range was from 20 to 60 years. Patients who demonstrated one or more of the following conditions were excluded from the present study: a history of central nervous system disease, substance abuse, schizophrenia, epilepsy, dementia or mental retardation. The ethics committee of Teikyo University Chiba Medical Center approved the study. Written informed consent was obtained from all participants after the procedures had been fully explained.

\subsection{Clinical Assessment}

At the first visit, patients were evaluated using the section on social phobia of the Mini-International Neuropsychiatric Interview (M.I.N.I.) [14]. The patients giving 
three or four affirmative answers to the four questions were evaluated by the Liebowitz Social Anxiety Scale (L-SAS) [15]. L-SAS examines two dimensions, fear/ anxiety and avoidance. We used the Japanese version, the reliability and validity of which has been confirmed [16]. Patients were diagnosed according to the Diagnostic and Statistical Manual and Mental Disorders, Fourth edition Text Revision, (DSM-IV) by senior-level psychiatrists. When a patient reported a depressive state, the patient's score on the 21-item Hamilton Rating Scale for Depression (HAM-D) was determined.

\subsection{Paroxetine Treatment}

Sixteen patients with both SAD and depression were recruited into the present study. Patients received paroxetine for 12 weeks. Doses were gradually increased form 10 to $40 \mathrm{mg} /$ day for the first 6 weeks and maintained $40 \mathrm{mg} /$ day for the last 6 weeks. Ten patients completed the treatment with paroxetine (62.5\%). Six patients were dropouts without any clear reasons (37.5\%).

\subsection{Statistical Analysis}

For statistical evaluation, one-way repeated measures analysis of variance (ANOVA) was performed to assess the overall differences between variables. Differences were considered to be significant when $\mathrm{p}$ values were less than 0.05 .

\section{RESULTS}

Of 293 patients, 63 patients scored 4 points and 40 patients scored 3 points on the social phobia section of the M.I.N.I. Among them, 21 of 63 patients (33\%) with 4 points and 16 patients of 40 patients (40\%) with 3 points on the M.I.N.I were diagnosed with SAD on DSM-IV. Thus, 37 patients with SAD (12.6\%) were found among 293 outpatients between the ages of 20 and 60. Among the 37 patients with SAD, 23 patients (62\%) suffered from depression on DSM-IV.

Sixteen patients with both SAD and depression were recruited into the present study. Ten patients (62.5\%) completed 12 weeks of treatment with paroxetine. The scores on the HAM-D were significantly decreased in proportion to treatment time (Figure 1(a)). Based on a $50 \%$ reduction of HAM-D scores, seven patients reached criteria, but three patients did not. Based on recovery from depression (HAM-D scores below 10), eight patients improved, one patient did not reach criteria, and one patient did not change.

The L-SAS scores decreased slightly without statistical significance (Figure 1(b)). From the viewpoint of recovery from SAD (L-SAS scores below 30), four patients improved, one patient did not reach criteria, and five patients did not change. Thus, the effects on SAD of

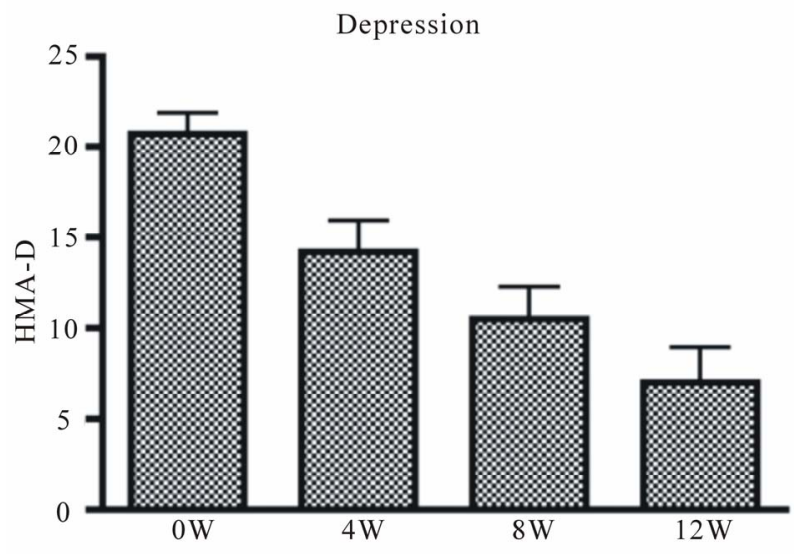

(a)

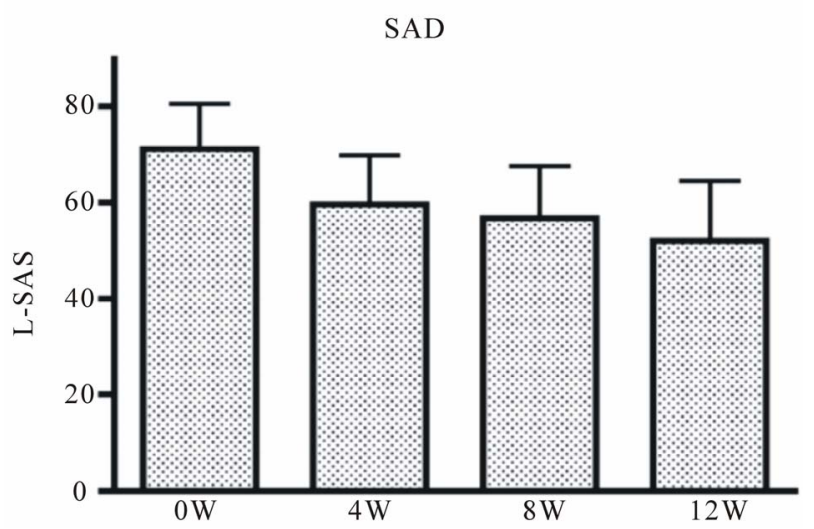

(b)

Figure 1. Paroxetine exerted more effective antidepressant effects on HAM-D than anti-SAD effects on L-SAS. (a) F (3.27) $=5.153, \mathrm{P}=0.0004$; (b) $\mathrm{F}(3.27)=1.778, \mathrm{P}=0.1650$.

paroxetine were less strong than its effects on depression. We did not find any difference between two dimensions, fear/anxiety and avoidance, in L-SAS scores of the patients with good outcomes (data not shown).

\section{DISCUSSION}

The present study reveals epidemiologic data about social affective disorder (SAD) in patients at a psychiatric outpatient clinic in Japan. The prevalence of SAD from 20- to 60-year-old patients, excluding those with central nervous system disease, substance abuse, schizophrenia, epilepsy, dementia or mental retardation at the outpatient clinic is $12 \%$.

Of the 293 patients, 63 patients scored 4 points and 40 patients scored 3 points on the section of social phobia on the M.I.N.I. Among them, 21 of 63 patients (33\%) with 4 points on the M.I.N.I. and 16 of 40 patients (40\%) with 3 points on the M.I.N.I. were diagnosed as SAD on DSM-IV. This result indicates that the M.I.N.I. score does not need full marks, but is diagnostic even at 3 points. 
The comorbidity of major depression $(n=23)$ in the patients with SAD $(n=37)$ was $62 \%$ in the present study. This is in a good agreement with a previous study (70\%) by Van Ameringen et al. [5]. Interestingly, a recent study reported that social phobia was strongly associated with the subsequent onset of major depressive disorder [8]. These results indicate that psychiatrists should consider the high rate of already-onset of both SAD and depression when they see patients at their first visit on the outpatient clinic of psychiatry.

Ten of 16 patients (62.5\%) completed the concurrent treatment study with paroxetine. This rate was similar to the previous report (around $60 \%$ for completion of the study) $[17,18]$. The high rate of dropout might be due to adverse reactions such as nausea, abnormal ejaculation, somnolence, and dizziness occurring at 15\% [19]. There may exist unknown reasons for the dropout, which are important for poor clinical outcomes. A previous study showed that the rate of discontinuation of paroxetine study in social phobia was $20 \%$ [20]. The precise reasons for the dropout remains to be elucidated.

Paroxetine showed broader effectiveness for the treatment of depression than for SAD (Figure 1). The recovery rate of depression was $80 \%$, whereas that of SAD was $40 \%$ according to the respective scores (HAM-D scores blow 10 and L-SAS scores below 30). This indicates that symptoms of SAD are not necessarily parallel with those of depression. Previous studies reported that the recovery rate of social phobia by paroxetine were $50 \%-70 \%$ [20-22]. This percentage is better than the present result. It seems that symptoms of depression are more responsive than those of SAD to the treatment with paroxetine in the Japanese patients with both SAD and depression.

In support of this, SAD and depression are different from the biological perspective of cortisol response to dfenfluramine administration. Patients with SAD had an augmented cortisol response to d-fenfluramine compared to healthy volunteers [23], while depressed patients had a response to d-fenfluramine that was similar to control subjects [24]. This pathology of the hypothalamic-pituitary-adrenal axis could be reflected in the different effects of paroxetine on SAD and depression seen in the present study, although this is speculation.

\section{REFERENCES}

[1] American Psychiatric Association (2000) Diagnostic and statistical manual of mental disorders. 4th Edition, Text Revision, American Psychiatric Association Inc., Washington DC.

[2] Davidson, J.R., Hughes, D.L., George, L.K. and Blazer, D.G. (1993) The epidemiology of social phobia: Findings from the duke epidemiological catchment area study. Psychological Medicine, 23, 709-718.

\section{doi:10.1017/S0033291700025484}

[3] Schneider, F.R., Heckelman, L.R., Garfinkel, R., Campeas, R., Fallon, B.A., Gitow, A., Street, L., Del Bene, D. and Liebowitz, M.R. (1994) Functional impairment in social phobia. Journal of Clinical Psychiatry, 55, 322331.

[4] Den Boer, J.A. (1997) Social phobia: Epidemiology, recognition, and treatment. British Medical Journal, 315, 796-800. doi:10.1136/bmj.315.7111.796

[5] Van Ameringen, M., Mancini, C., Styan, G. and Donison, D. (1991) Relationship of social phobia with other psychiatric illness. Journal of Affective Disorders, 21, 93-99. doi:10.1016/0165-0327(91)90055-W

[6] Stein, M.B., Tancer, M.E., Gelernter, C.S., Vittone, B.J. and Uhde, T.W. (1990) Major depression in patients with social phobia. American Journal of Psychiatry, 147, 637639.

[7] Souery, D., Oswald, P., Massat, I., Bailer, U., Bollen, J., Demyttenaere, Y., Montgomery, S., Serretti, A., Zohar, J. and Mendlewicz, J. (2007) Clinical factors associated with treatment resistance in major depressive disorder: Results from a European multicenter study. Journal of Clinical Psychiatry, 68, 1062-1070. doi:10.4088/JCP.v68n0713

[8] Tsuchiya, M., Kawakami, N., Ono, Y., Nakane, Y., Nakamura, Y., Tachimori, H., Iwata, N., Uda, H., Nakane, H., Watanabe, M., Naganuma, Y., Furukawa, T.A., Hata, Y., Kobayashi, M., Miyake, Y., Takeshima, T., Kikkawa, T. and Kessler, R.C. (2009) Lifetime comorbidities between phobic disorders and major depression in Japan: Results from the world mental health Japan 2002-2004 survey. Depression and Anxiety, 26, 949-955. doi:10.1002/da.20508

[9] Stein, M.B., Fuetsch, M., Müller, N., Höfler, M., Lieb, R. and Wittchen, H.U. (2001) Social anxiety disorder and the risk of depression. Archives of General Psychiatry, 58, 251-256. doi:10.1001/archpsyc.58.3.251

[10] Holma, K.M., Holma, I.A.K., Melartin, T.K., Rytsälä, H.J. E. and Isometsä, T. (2008) Long-term outcome of major depressive disorder in psychiatric patients is variable. Journal of Clinical Psychiatry, 69, 196-205. doi:10.4088/JCP.v69n0205

[11] Dalrymple, K.L. and Zimmerman, M. (2011) Treatmentseeking for social anxiety disorder in a general outpatient psychiatry setting. Psychiatry Research, 187, 375-381. doi:10.1016/j.psychres.2011.01.004

[12] Van Vliet, I.M., den Boer, J.A. and Westenberg, H.G. (1994) Psychopharmacological treatment of social phobia; a double blind placebo controlled study with fluvoxamine. Psychopharmacology, 115, 128-134. doi:10.1007/BF02244762

[13] Fedoroff, I.C. and Taylor, S. (2001) Psychological and pharmacological treatments of social phobia: A metaanalysis. Journal of Clinical Psycopharmacology, 21, 311324. doi:10.1097/00004714-200106000-00011

[14] Sheehan, D.V., Lecrubier, Y., Sheehan, K.H., Sheehan, H.K., Amorim, P., Janavas, J., Weiller, E., Hergueta, T., Baker, R. and Dunber, G.C. (1998) The mini-international neuropsychiatric interview (MINI): The development and validation of structured diagnostic psychiatric 
interview for DSM-IV and ICD-10. Journal of Clinical Psychiatry, 59, 22-33.

[15] Liebowitz, M.R. (1987) Social phobia. In: Ban, T.A., Pichot, P. and Poldinger, W., Eds., Modern Problems of Pharmacopsychiatry, Karger, New York, 141-173.

[16] Asakura, S., Inoue, S., Sasaki, F., Sasaki, Y., Kitagawa, N., Inoue, T., Denda, K., Ito, M., Matsubara, R. and Koyama, T. (2002) Reliability and validity of the Japanese version of the Liebowitz Social Anxiety Scale. Seishin Igaku, 44, 1077-1084.

[17] Van Ameringen, M. and Mancini, C. (2001) Pharmacotherapy of social disorder at the turn of the millennium. Psychiatric Clinics of North America, 24, 783-803. doi:10.1016/S0193-953X(05)70263-X

[18] Eaddy, M., Bramley, T. and Regan, T. (2003) Time to antidepressant discontinuation: A comparison of controlled-release paroxetine and immediate-release selective serotonin-reuptake inhibitors. Managed Care Interactive, 16, 22-27.

[19] Golden, R.N., Nemeroff, C.B., McSorley, P., Pitts, C.D. and Dubé, E.M. (2002) Efficacy and tolerability of controlled-release and immediate release paroxetine in the treatment of depression. Journal of Clinical Psychiatry, 63, 577-584. doi:10.4088/JCP.v63n0707

[20] Allgulander, C. (1999) Paroxetine in social anxiety dis- order: A randomized placebo-controlled study. Acta Psychiatrica Scandinavica, 100, 193-198.

doi:10.1111/j.1600-0447.1999.tb10845.x

[21] Stein, M.B., Liebowitz, M.R., Lydiard, R.B., Pitts, C.D., Bushnell, W. and Gerbel, I. (1998) Paroxetine treatment of generalized social phobia (social anxiety disorder): A randomized controlled trial. Journals of American Medical Association, 280, 708-713. doi:10.1001/jama.280.8.708

[22] Baldwin, D., Bobes, J., Stein, D.J., Scharwächter, I. and Faure, M. (1999) Paroxetine in social phobia/social anxiety disorder. Randomized double-blind, placebo-controlled study. Paroxetine study group. British Journal of Psychiatry, 175, 120-126. doi:10.1192/bjp.175.2.120

[23] Tancer, M.E., Mailman, R.B., Stein, M.B., Mason, G.A., Carson, S.W. and Golden, R.N. (1994-1995) Neuroendocrine responsivity to monoaminergic system probes in generalized social phobia. Anxiety, 1, 216-223.

[24] Duval, F., Mokrani, M.C., Correa, H., Bailey, P., Valdebenito, M., Monreal, J., Crocq, M.A. and Macher, J.P. (2001) Lack of effect of HPA axis hyperactivity on hormonal responses to d-fenfluramine in major depressed patients: Implications for pathogenesis of suicidal behaviour. Psychoneuroendocrinology, 26, 521-537. doi:10.1016/S0306-4530(01)00011-7 